\title{
Stream Discharge Response to Climate Change and Land Use Change in Tamor Basin, Nepal
}

\author{
* K.C. Sumitra, R.P. Shrestha and S. Shrestha \\ Asian Institute of Technology, Pathumthani, Thailand \\ *Email: sumitrakc17@gmail.com
}

\begin{abstract}
Climate change and land use change are two major issues that need to be addressed for sustainable land and water resource management. These are major factors influencing discharge in monsoon dominated basin. This study aims to quantitatively assess the impact of climate change and land use change on future discharge of the Tamor basin in Nepal. Result from the study indicated maximum temperature will reach to $40.63^{\circ} \mathrm{C}$ in $2030 \mathrm{~s}, 40.63^{\circ} \mathrm{C}$ in $2060 \mathrm{~s}$ and $45.95^{\circ} \mathrm{C}$ in 2090 s which was $35^{\circ} \mathrm{C}$ in baseline period (1976-2005). Annual average precipitation was projected to change by $17.64 \%$ under RCP 4.5 and by $39.88 \%$ under RCP 8.5 till the end of the century as projected by HadGEM2. Since the basin is monsoon dominated, annual discharge was projected to increase by $12.25 \%$ under RCP 4.5 and by $32.67 \%$ under RCP 8.5 above baseline average till the end of the century. Result using HadGEM2 also shows that peak flows that used to occur in August in baseline period will shift to July except in 2030s under RCP 4.5. However, CSIRO-Mk3.6.0 projects decrease in annual precipitation and hence also discharge at the end of the century. Result from both Global Climate Models show that average monthly discharge due to climate change will change positively as well as negatively for both scenarios. Due to combined impact of land use change and climate change, annual discharge was projected to change by $16.53 \%, 21.28 \%$ and $-4.39 \%$ under RCP 4.5 and by $38.29 \%, 45.64 \%$ and $13.06 \%$ under RCP 8.5 till the end of the century for conversion of forest into agricultural land, conversion of forest into barren land and conversion of barren land into forest respectively. Average annual discharge increased the most in case of conversion of forest into barren land and decreased or increased the least in case of conversion of barren land into forest. Unlike annual, seasonal response to combined impact was different. In monsoon and pre monsoon, discharge increased or decreased the least in case of conversion of forest into agricultural land and barren land while increased the least or decreased in case of conversion of barren land into forest. However, in post monsoon and winter, discharge decreased the least or increased the most in case of conversion of barren land into forest but discharge decreased the most or increased the least in case of conversion of forest into agricultural land and barren land.
\end{abstract}

Indexed Terms- Climate Change; Land Use Change; Stream Discharge

\section{INTRODUCTION}

Mountain ranges of Nepal, Bhutan and some part of India are known as Himalayas [1-3]. Approximately 1.3 billion people directly rely on river basins of the Hindu Kush Himalayan region for their livelihood [4] as ten largest Asian rivers have their origin this region. Climate in Himalayan region is governed by summer and winter monsoon system of Asia. Monsoon precipitation and melting of snow and glacier are major sources of water. 
Impact of climate change is unavoidable. Warming of climate has already altered temperature, precipitation pattern across the globe. Due to change in elevation in short distance, impact are expected to be more severe in Himalayan regions [5]. Due to rise in temperature, there are evident of precipitation in the form of snowfall being replaced by precipitation in the form of rainfall [6]. Further, melting of snow also increases. Consequence is chances of flood due to excess water in monsoon season and little or no water in rest of the year. The situation is further aggravated due to land transformation such as clearing of forest for agricultural expansion which is taking place at alarming rate in the region to fulfill demands of growing population. Clearing of forest increases surface runoff and river discharge [7] increasing risk of flood.

Whole part of Nepal lies in Hindu Kush Himalayan region. The summer monsoon dominates the climate, lasting eight months (March to October) in the Eastern Himalayas, four months (June to September) in the Central Himalayas, and two months (July to August) in the Western Himalayas [8]. Clearing of forest for agricultural expansion and other infrastructure development are also very common practices in Nepal. It is more common especially in hilly and mountain regions where people are dependent on forest for fuel and fodder [9]. Regarding the coupled effect of climate change and land use change, effect of one can offset other or enhance the effect [10] but least studies have done incorporating combined impact of climate change and land use change. There is lack of coherent studies of the situation, where climate and land uses are changing, to balance too much or too little of water and to fulfill increasing demand for water [11]. Further, impact of climate change varies at global scale and local scale and cannot be generalized [12]. Stream discharge assessment is considered as indicator for providing insights into long term hydro-climatic changes because stream discharge is integrated response to temperature, precipitation and land use of the basin [13]. The objective of this research is to study impact of Climate Change and Land Use Change on stream discharge of Tamor Basin in Nepal. Eastern Himalayan region of Nepal is more sensitive to climate change than western Himalayas as monsoon precipitation, major source of water contribution in the region, starts from the eastern region and weakens towards the western region [14]. Therefore, Tamor has longer monsoon period. Also, rainy season and melting season occurs at the same time and this further complicates the understanding of hydrology of the river basin [15]. Tamor basin has already experienced 33 floods and 149 landslide events between 1971 and 2011 in the past [16]. Tamor basin has also undergone massive deforestation in the past.

\section{STUDY AREA}

Tamor basin in the eastern region of Nepal has been selected as study area. Tamor river is one of the tributaries of Saptakoshi river and hence sub-basin of Saptakoshi which is also known as Koshi in short. This river originates from Mt. Kanchanjunga. The Tamor river basin extends from $228 \mathrm{~m}$ to $8586 \mathrm{~m}$ within around $100 \mathrm{~km}$ of latitudinal distance, with an average elevation of 2862 masl [3]. Its total area is $5863.19 \mathrm{~km}^{2}$. It ends at Tribeni where it joins with Sunkosi and Arun River. The total length of this river is about $190 \mathrm{~km}$. Basin's centroid lies at latitude of $27.24^{\circ}$ and longitude at $87.74^{\circ}$. The Tamor sub-basin is considered as an earth's biodiversity hotspot [17]. Nine rainfall stations and four temperature stations are considered in this study. Tamor basin has two gauging stations-Mulghat (276 masl) and Majhitar (533 masl). Only Mulghat station is considered in this study. Figure 1 represents location of hydro-meteorological stations in Tamor. 


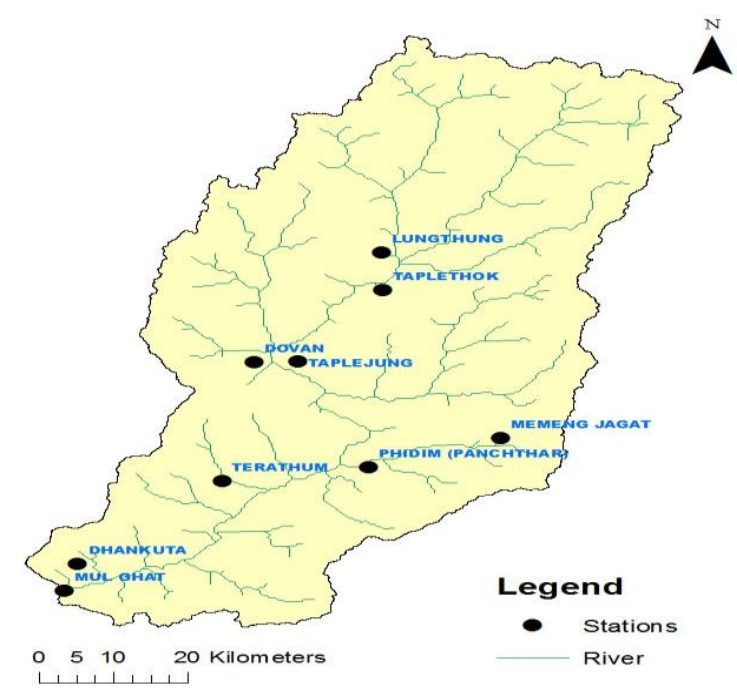

Figure 1: Hydro-Meterological station locations in Tamor Basin

Average annual maximum temperature is $22.21{ }^{\circ} \mathrm{C}$ and average annual Minimum temperature is 12.78 ${ }^{\circ} \mathrm{C}$. Average monthly maximum temperature is $27.03{ }^{\circ} \mathrm{C}$ for June and minimum temperature is $5.83^{\circ} \mathrm{C}$ in January. Average annual precipation is $1602.86 \mathrm{~mm}$. Highest average monthly precipitation is $384.68 \mathrm{~mm}$ in July.

\section{METHODOLOGY}

In this study, secondary data was collected from Department of Hydrology and Meteorology, ICIMOD and Land Survey Nepal. Further data on future climate is downloaded and bias corrected. Study area was divided into 19 sub-basins and the downscaled GCM data was used for each of the sub-basins. Threshold values for Land use, Soil and Slope were 10\%, 15\% and 15\% respectively. Slopes were categorized into 4 classes- 0-15, 15-30, 30-45 and 45-99. Altogether 119 HRUs were created for 19 sub-basins. Based on previous use of models in in the vicinity of Tamor basin suitable two GCMs- HadGEM2 and CSIRO-Mk3.6.0 were selected. Data from 1976-2005 for historical and 2006-2100 under RCP 4.5 and RCP 8.5 were downloaded. Downloaded data were in NETCDF format which were then extracted for Tamor basin using ArcGIS. Linear Scaling method was used for the bias correction of temperature and precipitation of future climate data.

$$
\begin{aligned}
& \mathrm{P}_{\text {contr }}^{*}(\mathrm{~d})=\mathrm{P}_{\text {contr }}(\mathrm{d})\left[\frac{\mu_{m\left(P_{\text {obs }}(d)\right)}}{u_{m\left(P_{\text {contr }}(d)\right)}}\right] \\
& \mathrm{P}_{\text {scen }}^{*}(\mathrm{~d})=\mathrm{P}_{\text {scen }}(\mathrm{d})\left[\frac{\mu_{m\left(P_{\text {obs }}(d)\right)}}{u_{m\left(P_{\text {contr }}(d)\right)}}\right] \\
& \mathrm{T}^{*}{ }_{\text {contr }}(\mathrm{d})=\mathrm{T}_{\text {contr }}(\mathrm{d})+\boldsymbol{\mu}_{\mathrm{m}}\left(\mathrm{T}_{\text {obs }}(\mathrm{d})\right)-\boldsymbol{\mu}_{\mathrm{m}}\left(\mathrm{T}_{\text {contr }}(\mathrm{d})\right) \\
& \mathrm{T}^{*}{ }_{\text {scen }}(\mathrm{d})=\mathrm{T}_{\text {scen }}(\mathrm{d})+\boldsymbol{\mu}_{\mathrm{m}}\left(\mathrm{T}_{\text {obs }}(\mathrm{d})\right)-\boldsymbol{\mu}_{\mathrm{m}}\left(\mathrm{T}_{\text {contr }}(\mathrm{d})\right)-
\end{aligned}
$$

$\mathrm{P}_{\text {scen }}=$ Future daily simulated Precipitation

$\mathrm{P}_{\mathrm{obs}}=$ Observed daily Precipitation data

$\mathrm{P}_{\text {contr }}=$ Daily historical raw simulated precipitation 
$\boldsymbol{\mu}_{\mathrm{m}}=$ Mean daily Precipitation/temperature for particular month

$\mathrm{T}_{\mathrm{obs}}=$ Daily observed Temperature

$\mathrm{T}_{\text {scen }}=$ Future daily simulated Temperature

$\mathrm{T}_{\text {contr }}=$ Daily historical raw simulated temperature

\section{CALIBRATION AND VALIDATION}

Calibration period was taken from 1990-1999 and validation period from 2000-2006. Monthly Calibration values for $\mathrm{R}^{2}$, NSE and PBIAS were obtained to be $0.88,0.85$, and $1.57 \%$ respectively, likewise monthly validation values were $0.93,0.86$ and $8.48 \%$ respectively. In the years, 2000-2003 in validation period, simulated peaks are underestimated. SWAT model was unable to capture peak flows in this study. Similar results have been obtained in other studies as well. SWAT model fails to capture peak flows [18]. This might be because rainfall data used were not representative to capture peak flows as model uses data from the rainfall station that is near to the centroid of the sub basin [19]. Likewise daily calibration values for $\mathrm{R}^{2}$, NSE, and PBIAS were obtained to be $0.77,0.78$ and $1.70 \%$ respectively. Likewise, $\mathrm{R}^{2}$ equal to 0.81 , NSE equal to 0.79 and PBIAS equal to $7.74 \%$ was obtained for validation period. Graphical performance for daily calibration and validation is presented in Figure 4 and 5 respectively. In calibration period from 1996-1999 model was not able to capture peak flows. Similarly, during validation period peak simulated flows are underestimated compared to observed flows. This might be attributed to precipitation pattern, accuracy of measured precipitation and discharge, where errors are more pronounced at extreme high and low periods [20-22]. However, pattern of low flow is well captured by the model.

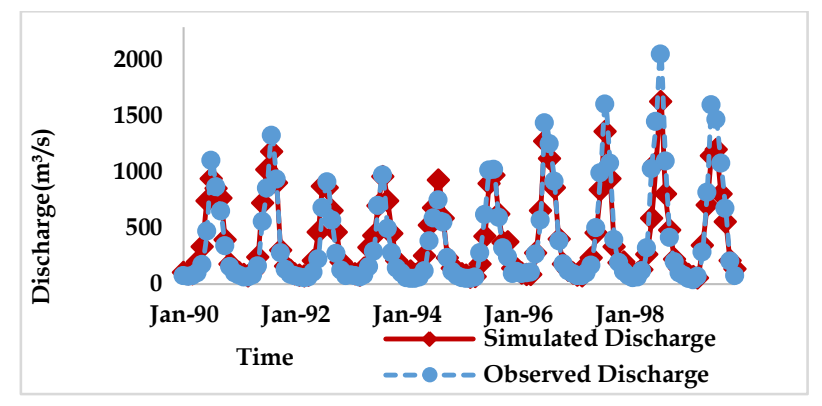

Figure 2: Calibration for monthly discharge from 1990-1999 for Mulghat Station

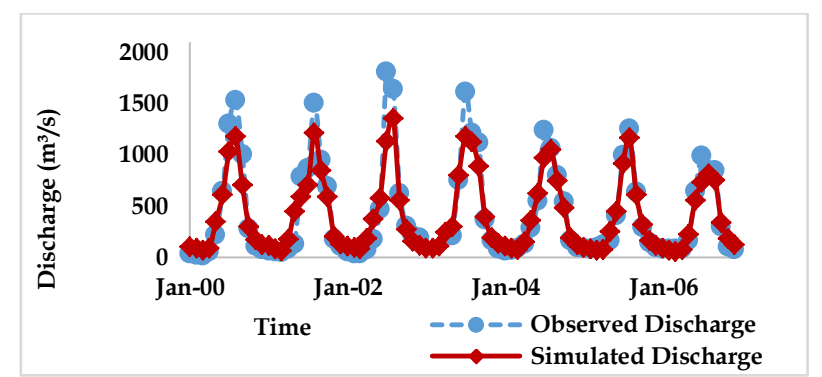

Figure 3: Validation for monthly discharge from 2000-2006 for Mulghat Station 


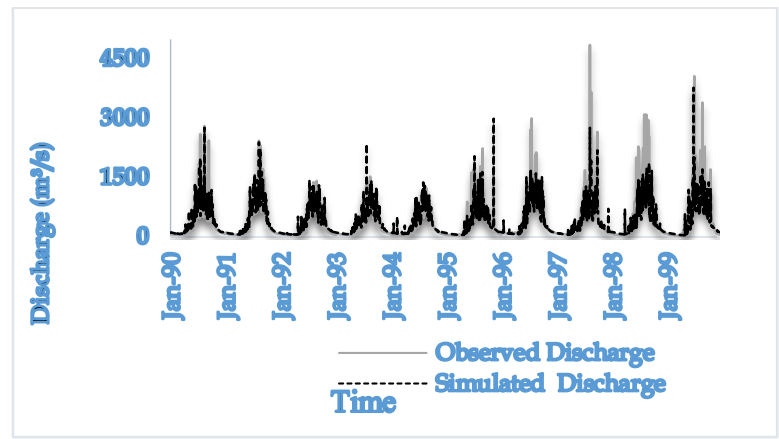

Figure 4: Calibration for daily discharge from 1990-1999 for Mulghat Station



Figure 5: Validation for daily discharge from 2000-2006 for Mulghat Station

\section{FUTURE ANNUAL DISCHARGE DUE TO CLIMATE CHANGE}

Warm up period was used from 1988-1989 which stabilize parameters and replicate the actual condition of basin [23]. When annual discharge was plotted, increasing trend was obtained in case of HADGEM2 as shown in Figure 6 under both RCP scenarios 4.5 and RCP 8.5. Annual average discharge of Tamor in baseline period was $310.27 \mathrm{~m} / \mathrm{s}$. In 2021, average annual discharge projected was $314.07 \mathrm{~m}^{3} / \mathrm{s}$ under RCP 4.5 and $279 \mathrm{~m}^{3} / \mathrm{s}$ under RCP 8.5 . In 2040, average annual discharge obtained was $301.18 \mathrm{~m}^{3} / \mathrm{s}$ and $344.43 \mathrm{~m}^{3} / \mathrm{s}$ under RCP 4.5 and 8.5 respectively. In 2071, average annual discharge increased to $347.69 \mathrm{~m} \mathrm{3} / \mathrm{s}$ and $397.19 \mathrm{~m}^{3} / \mathrm{s}$. In the year 2100 , average annual discharge was projected to increase to $405.61 \mathrm{~m}^{3} / \mathrm{s}$ and $340.03 \mathrm{~m}^{3} / \mathrm{s}$ under RCP 4.5 and 8.5 respectively. Increase in annual maximum and minimum discharges in other basins in Nepal has also been reported [24]. 


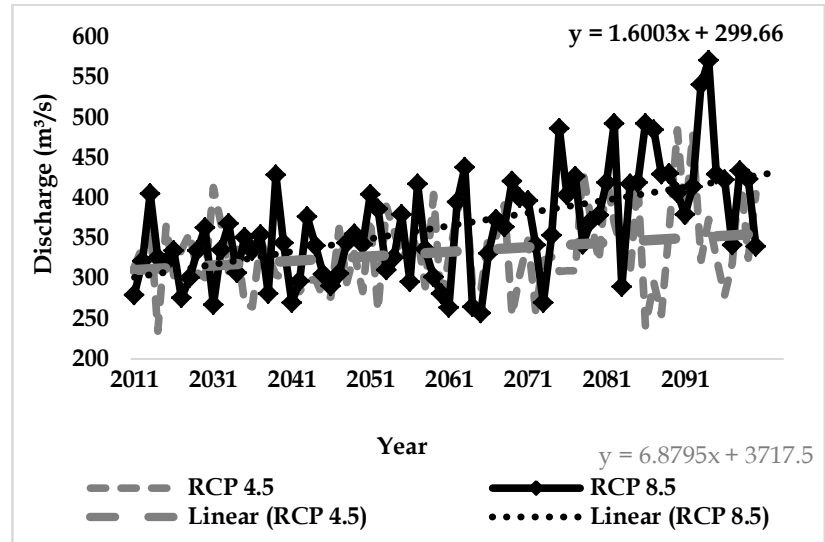

Figure 6: Validation for daily discharge from 2000-2006 for Mulghat Station

\section{FUTURE MONTHLY DISCHARGE DUE TO CLIMATE CHANGE IN TAMOR BASIN}

Hydrograph depicting future discharge under RCP scenarios 4.5 and 8.5 using HadGEM2 are shown in Figure 7 and 8 respectively. From the hydrograph, it can be concluded that future discharge is higher than the baseline period. In case of HadGEM2, highest future discharge has been predicted for 2090s. Increasing and decreasing trend of discharge was found to match precipitation pattern of the same time period for both scenarios of respective climate models which is considered as the main contributing factor in case of Nepal.

When future discharge was assessed monthly, results indicated shift of peak flow. In baseline period, peak discharge was observed in August, however, under RCP 4.5 July received peak discharge in 2060s and 2090s. Likewise, July received peak discharge in all future periods under RCP 8.5.

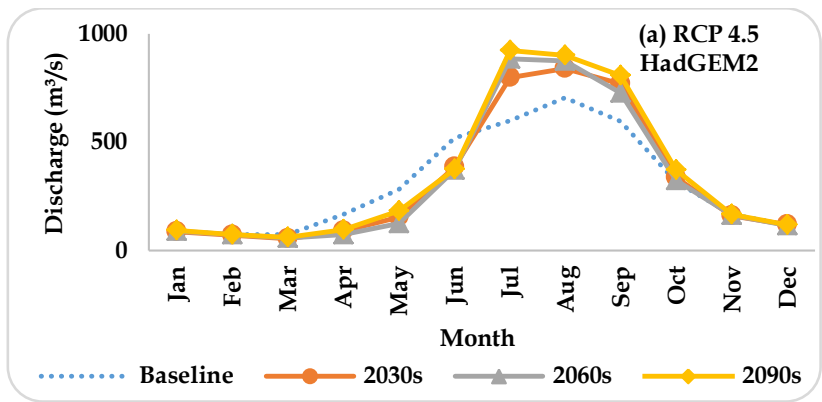

Figure 7: Average Discharge under RCP 4.5 (HadGEM2)

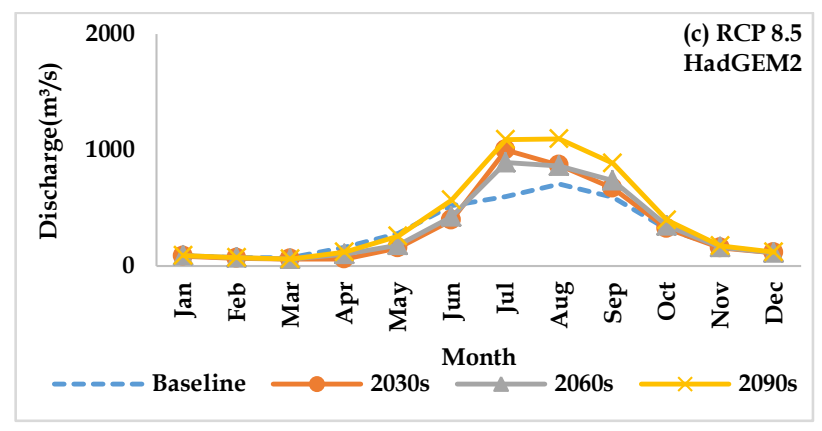

Figure 8: Average Discharge under RCP 8.5 (HadGEM2) 
In Figure 9, light grey, dark grey band represent range of minimum and maximum discharge under RCP scenario 4.5 (HadGEM2). Similarly, error band represent range of minimum and maximum discharge of baseline period (1976-2005). Projected peak flows exceeding baseline high flows were found to be very frequent in wet months implying that climate change is likely to have prominent impact on seasonal discharge. Peak flows exceeded baseline peak flows mostly in wetter months. Similar results were also found under RCP 8.5 as well.

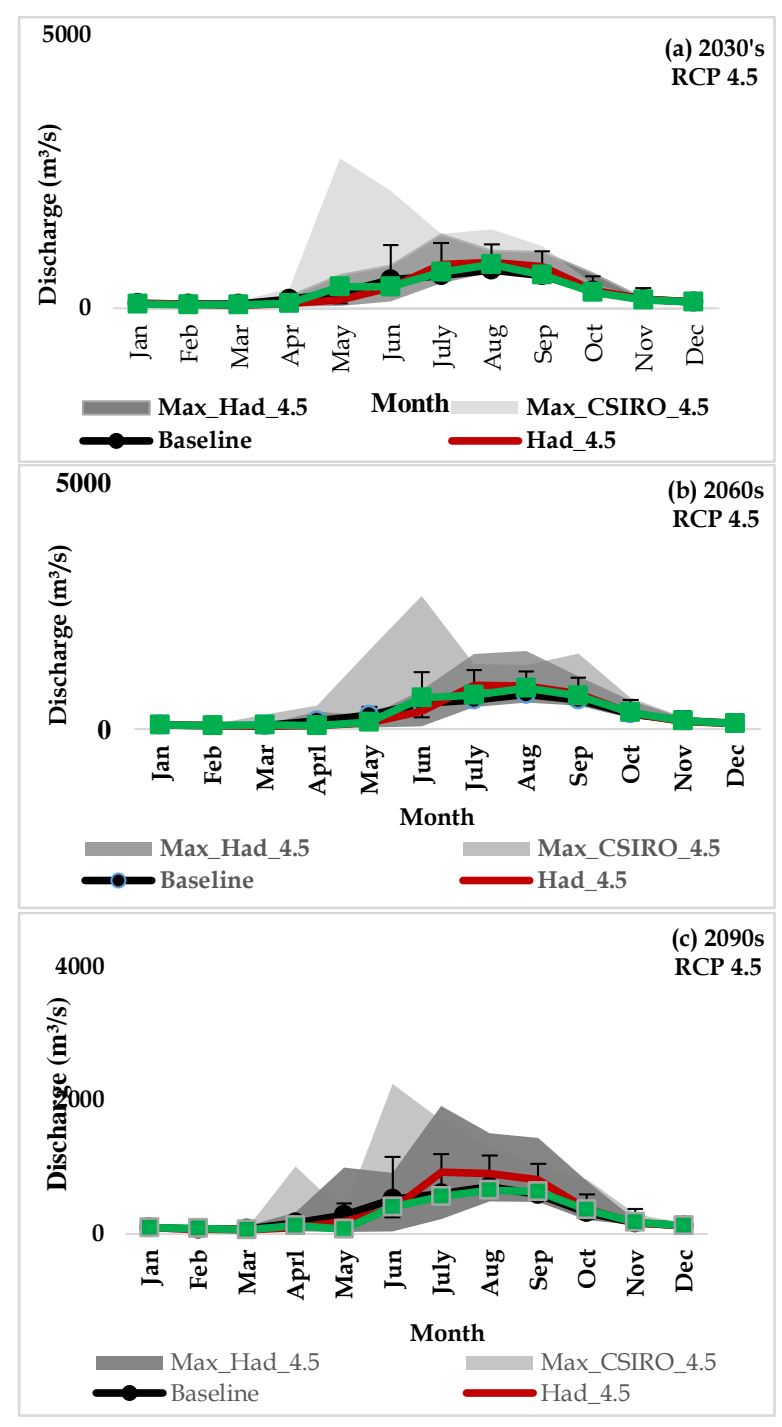

Figure 9: Monthly discharge for baseline period \& 2030s, 2060s, 2090s under RCP 4.5

\section{FUTURE ANNUAL DISCHARGE DUE TO COMBINED IMPACT OF CLIMATE CHANGE AND LAND USE CHANGE}

In order to assess combined impact of Land Use Change and Climate Change on stream discharge, average annual discharge for future periods-2030s, 2060s and 2090s - for hypothetical land use change scenarios - conversion of forest into agricultural land (S1), conversion of forest into barren land (S2) and conversion of barren land into forest (S3) - was compared with average annual discharge for future period without land use change (S0). 
Table 1: Hypothetical land use scenarios

\begin{tabular}{|c|c|c|c|c|c|c|c|}
\hline $\begin{array}{l}\text { Scenari } \\
\mathrm{o}\end{array}$ & Year & Forest (\%) & $\begin{array}{l}\text { Agriculture } \\
(\%)\end{array}$ & $\begin{array}{l}\text { Barren } \\
\text { land }(\%)\end{array}$ & $\begin{array}{l}\text { Pasture } \\
\text { land }(\%)\end{array}$ & $\begin{array}{l}\text { Shrub } \\
\text { land }(\%)\end{array}$ & $\begin{array}{l}\text { Water } \\
(\%)\end{array}$ \\
\hline \multirow[t]{2}{*}{ So } & 2000 & 30.56 & 30.41 & 23.23 & 9.85 & 1.20 & 4.76 \\
\hline & $2011-2040$ & 25.30 & 35.67 & 23.23 & 9.85 & 1.20 & 4.76 \\
\hline \multirow[t]{3}{*}{$\mathrm{S} 1$} & $2041-2070$ & 20.29 & 40.68 & 23.23 & 9.85 & 1.20 & 4.76 \\
\hline & $2071-2100$ & 12.77 & 48.20 & 23.23 & 9.85 & 1.20 & 4.76 \\
\hline & $2011-2040$ & 24.71 & 30.41 & 29.08 & 9.85 & 1.20 & 4.76 \\
\hline \multirow[t]{3}{*}{$\mathrm{S} 2$} & $2041-2070$ & 19.13 & 30.41 & 34.66 & 9.85 & 1.20 & 4.76 \\
\hline & $2071-2100$ & 10.77 & 30.41 & 43.02 & 9.85 & 1.20 & 4.76 \\
\hline & $2011-2040$ & 33.88 & 30.41 & 19.91 & 9.85 & 1.20 & 4.76 \\
\hline \multirow[t]{2}{*}{ S3 } & $2041-2070$ & 37.04 & 30.41 & 16.75 & 9.85 & 1.20 & 4.76 \\
\hline & $2071-2100$ & 41.62 & 30.41 & 12.17 & 9.85 & 1.20 & 4.76 \\
\hline
\end{tabular}

Hypothetical land use scenarios were created from existing land use map based on the past trend of land use change.

Results indicated that average annual discharge increased when forest land was converted to agriculture land (S1 Scenario) and when forest land was converted into barren land (S2 scenario) compared to result obtained for no land use change (S0 scenario). However, in case of conversion of barren land into forested land (S3), decrease in discharge was observed. Results obtained were similar under RCP 4.5 and RCP 8.5 for both GCMS but magnitude of change varied in different time periods and climate change scenarios. Average Annual discharge for future periods under different climate change and land use scenarios are presented where bar represents average annual discharge and error bar represents maximum and minimum discharge. Maximum and minimum discharge was also found to increase in S1 and S2 scenario and decrease in case S3 for all three future time periods for RCP 4.5 and RCP 8.5.

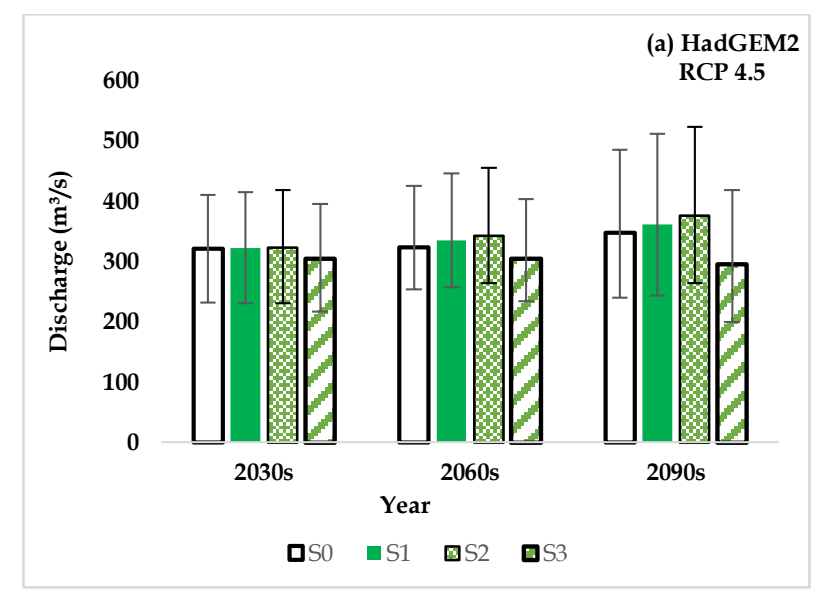

Figure 10: Average annual discharge due to Climate Change and Land Use Change under RCP 4.5 


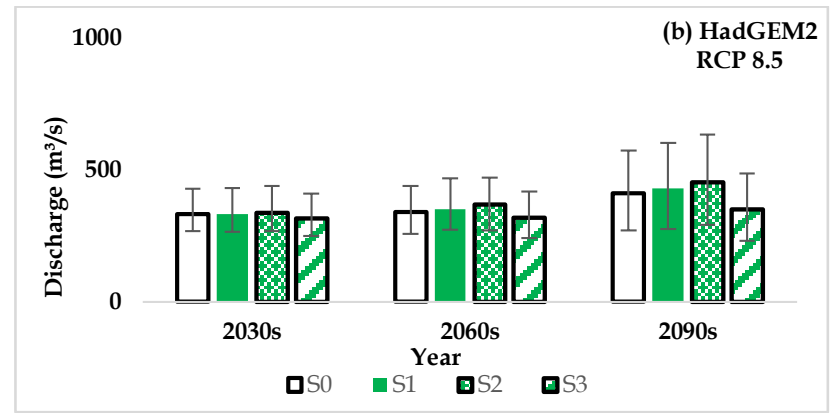

Figure 11: Average annual discharge due to Climate Change and Land Use Change under RCP 8.5

Figure 12 depicts change in average annual discharge. In all the cases average annual discharge increased with decrease in vegetation cover. Increase in average annual discharge was highest in case of conversion of forested land into barren land (S2) for all cases.

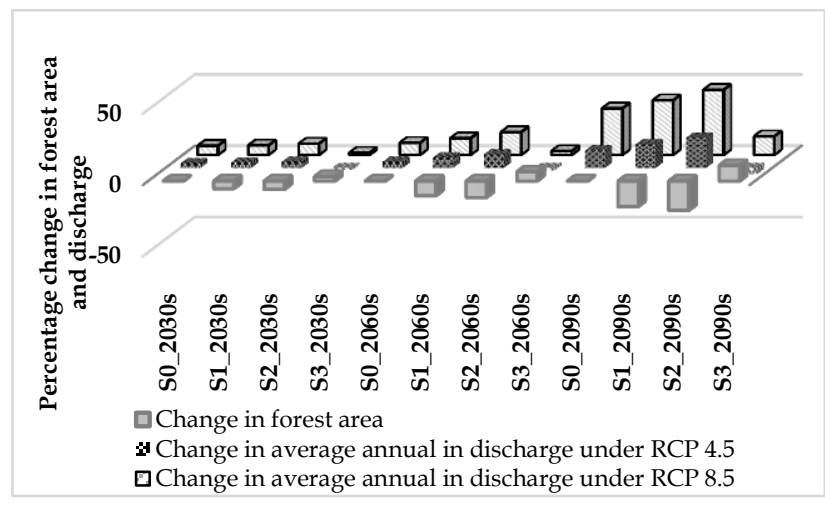

Figure 12: Change in Average annual discharge

\section{FUTURE SEASONAL DISCHARGE DUE TO COMBINED IMPACT OF CLIMATE CHANGE AND LAND USE CHANGE}

Figure 13-16 shows change in seasonal discharge due to combined impact of climate change and land use change under RCP 4.5 .

Seasonal impact of climate change and land use change on Tamor basin discharge was also assessed. Results obtained for seasonal discharge was different to that of Annual discharge. In Monsoon period that extends from June-September, in each future time period, average discharge and maximum discharge is highest in case of conversion of forest into barren land (S2 scenario) and lowest in case of conversion of barren land into forest (S3). Also, average and maximum discharge in all time periods and scenarios were above baseline maximum and average indicating excess water in monsoon in future.

Increase in discharge in Monsoon period is due to the fact that more than $79.08 \%$ of annual precipitation takes place in this season and snow melting also takes place around same time. Discharge increases further due to decline in forest area because of increase in surface runoff and decrease in infiltration. Increase in surface runoff is more for barren land compared to agricultural land. Possibilities of flood is more in Monsoon due to already concentrated precipitation but situation is exacerbated due to land use change (conversion of forest into agricultural land and barren land). Increase in discharge in case conversion of forest into barren land is more prominent. But due to increase in forest cover (conversion of barren land into forest) water is retained by complex root 
system of trees and considerable amount of water is lost by evapo-transpiration process resulting in decrease in discharge. This not only reduces chance of flooding during Monsoon but also secures water in soil profile for dry season where precipitation is null or less.

In Post Monsoon season that extends October-November, unlike Monsoon season, while comparing land use change scenarios discharge either decreased or increased the least in case of loss of forest cover (conversion of forest into agricultural land and conversion of forest into barren land). But discharge increased or decreased the least in case of conversion of barren land into forest (S3). Decrease in discharge in case of loss of forest cover (S1 and S2) can be attributed to loss of monsoon rain as excess surface runoff due to reduction of infiltration in monsoon season leaving insufficient amount of water in the soil profile for subsequent months. Besides precipitation in Post Monsoon is also low. Post monsoon discharge also relies on slow release of water that undergo infiltration in Monsoon. Likewise, when there is increase in forest cover such as conversion of barren land into forest (S3) in this study, discharge was projected to increase or decrease the least in Post Monsoon. This can be attributed to increase in infiltration due to complex root system of forest. Water that enters into soil profile is retained and released slowly contributing to discharge in subsequent months.

In Winter that extends from December to February, similar results were obtained as with Post Monsoon where discharge decreased or increased the least in case of loss forest area (conversion of forest into agricultural land and conversion of forest into barren land). This due to loss of forest area, surface runoff increases but infiltration decreases and as consequence monsoon rain is wasted as excess runoff during Monsoon leaving less or little in soil profile for coming months. Opposite of this holds for conversion of barren land into forest area (S3): water is retained by roots of the trees and water left after evapo-transpiration is slowly released in subsequent months.

In Pre-Monsoon, result similar to Monsoon was obtained. Precipitation in Pre-Monsoon is lower than in Monsoon but higher when compared to winter and post monsoon. Due to this factor, seasonal behavior to land use change was found to follow same pattern as in Monsoon season where discharge increased or decreased the least in case of decrease in forest cover ( 1 1 and S2) whereas decreased or increased the least in case of S3. Similar results were obtained for RCP 8.5 as well.

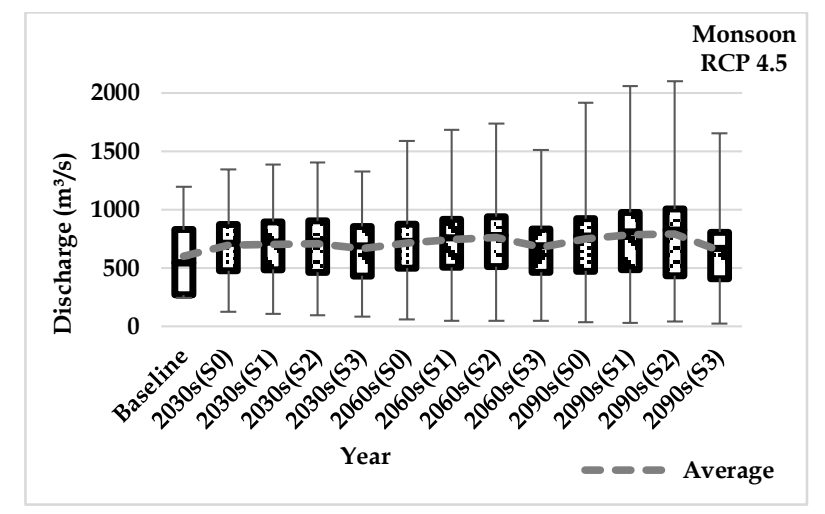

Figure 13: Discharge in Monsoon for land use scenarios under RCP 4.5

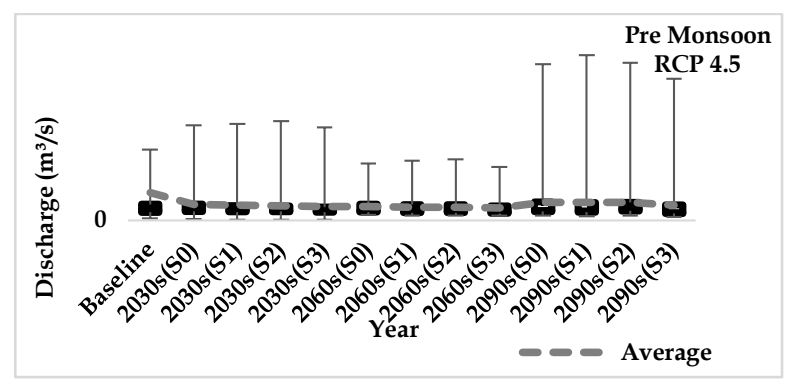


Figure 14: Discharge in Pre Monsoon for land use scenarios under RCP 4.5

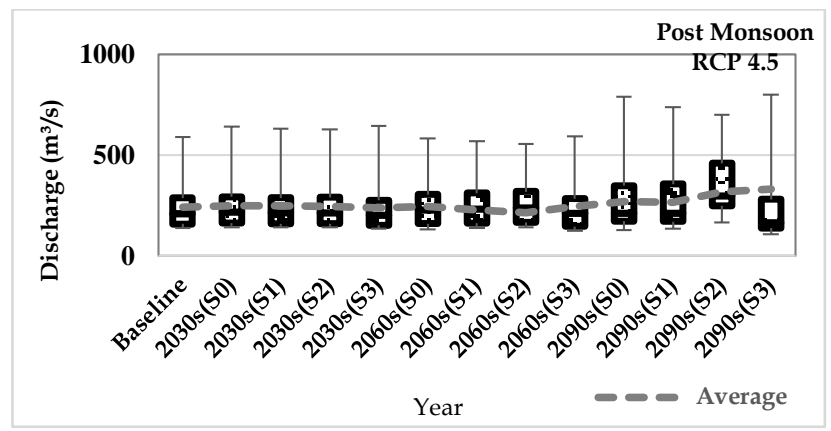

Figure 15: Discharge in Post Monsoon for land use scenarios under RCP 4.5

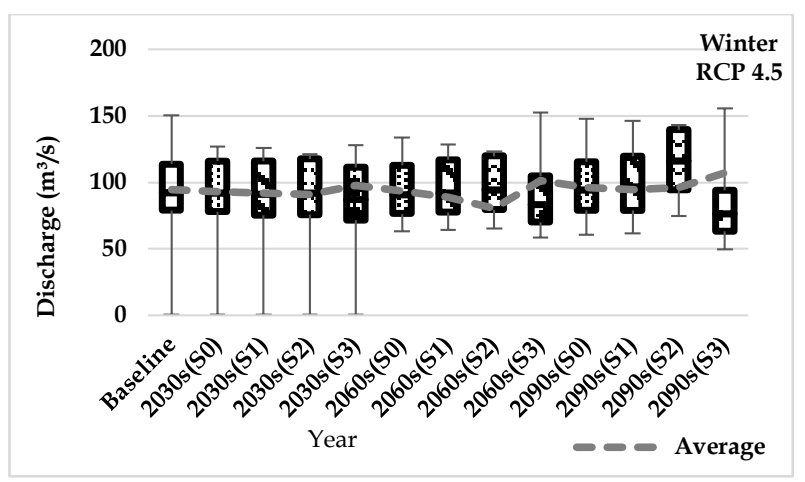

Figure 16: Discharge in Post Monsoon for land use scenarios under RCP 4.5

\section{CONCLUSIONS}

Due to climate change monthly discharge will change both positively and negatively. Monthly discharge will increase mostly in wetter months and decrease in drier months which is attributed to precipitation pattern in respective time periods which is major contributing factor. Peak flows are projected to shift from August to July in future periods.

Due to combined impact of climate change and land use change, annual discharge increases when forest cover is decreased. Likewise decrease in annual discharge takes place due to increase in forest cover. Unlike annual discharge, seasonal response to combined impact of climate change and land use change is different. In Monsoon season where more than $79.08 \%$ of precipitation is concentrated, due to loss of forest area (conversion of forest into agricultural land and conversion of forest into barren land) discharge will increase but will decrease in case of increase in forest area (conversion of barren land into forest). Results show similar pattern of discharge in Pre Monsoon as in monsoon. In Post Monsoon and winter, unlike Monsoon and Pre Monsoon, discharge will decrease due to loss of forest cover (conversion of forest into agricultural land and conversion of forest into barren land) and will increase when forest area is increased (conversion of barren land into forest). Forests play important role in preventing high flows that can lead to flood in wet seasons and water scarcity in dry season. 


\section{REFERENCES}

[1] Bolch, T., Kulkarni, A., Kääb, A., Huggel, C., Paul, F., Cogley, J. G., ... Stoffel, M. (2012). The state and fate of Himalayan glaciers. Science (New York, N.Y.), 336(6079), 310-314. doi:10.1126/science.1215828

[2] Yao, T., Thompson, L., Yang, W., Yu, W., Gao, Y., Guo, X., ... Joswiak, D. (2012). Different glacier status with atmospheric circulations in Tibetan Plateau and surroundings. Nature Climate Change, 2(9), 663-667. doi:10.1038/nclimate1580

[3] Panday, P. K., Williams, C. a., Frey, K. E., \& Brown, M. E. (2013). Application and evaluation of a snowmelt runoff model in the Tamor River basin, Eastern Himalaya using a Markov Chain Monte Carlo (MCMC) data assimilation approach. Hydrological Processes, 5353, 37-53. doi:10.1002/hyp.10005

[4] Vaidya, R. A., \& Sharma, E. (2014). Research Insights on Climate and Water in the Hindu Kush Himalayas. (R. A. Vaidya \& E. Sharma, Eds.) (p. 180). Kathamandu: ICIMOD.

[5] Whiteman, D. (2000). Mountain Meteorology: Fundamentals and Applications (p. 376).

[6] McCarty, J. P. (2001). Ecological Consequences of Recent Climate Change. Conservation Biology, 15(2), 320-331. doi:10.1046/j.1523-1739.2001.015002320.x

[7] Costa, M. H., Botta, A., \& Cardille, J. a. (2003). Effects of large-scale changes in land cover on the discharge of the Tocantins River, Southeastern Amazonia. Journal of Hydrology, 283, 206217. doi:10.1016/S0022-1694(03)00267-1

[8] Chalise, S. R. (2001). An introduction to climate, hydrology and landslide hazards in the hindu kush-himalayan region. In L. Tianchi, S. R. Chalise, \& B. N. Upreti (Eds.), Landslide Hazard Mitigation in the Hindu Kush-Himalayas (pp. 51-62).

[9] Nepal, G., Devkota, D. C., \& Bhattarai, T. N. (2012). Mountain Environment and Climate Change in Nepal. Ministry of ENviornment, Nepal (p. 56).

[10] Tu, J. (2009). Combined impact of climate and land use changes on streamflow and water quality in eastern Massachusetts, USA. Journal of Hydrology, 379(3-4), 268-283. doi:10.1016/j.jhydrol.2009.10.009

[11] Fleiner, R. (2013). Environment in the Koshi River Basin: Research status and future prospects.

[12] Immerzeel, W. W., \& Beek, Ludovicus, P.H. van Bierkens, M. F. P. (2010). Climate Change will affect the Asian Water Towers. Journal of Hydrology, (July), 1382-1385.

[13] Gautam, M. R., \& Acharya, K. (2012). Streamflow trends in Nepal. Hydrological Sciences Journal, 57(February), 344-357. doi:10.1080/02626667.2011.637042

[14] Bookhagen, B., \& Burbank, D. W. (2010). Toward a complete Himalayan hydrological budget: Spatiotemporal distribution of snowmelt and rainfall and their impact on river discharge. Journal of Geophysical Research: Earth Surface, 115, 1-25. doi:10.1029/2009JF001426

[15] Nepal, S. (2012). Evaluating Upstream-Downstream Linkages of Hydrological Dynamics in the Himalayan Region. 2012. Freidrich-Schiller University.

[16] Pathak, D. (2014). Water Induced Disaster in Tamor River Sub-Basin, East Nepal. DWIDP Bulletin (pp. 6-11).

[17] Shrestha, J., Singh, D. M., \& Saund, T. B. (2009). Fish Diversity of Tamor River and Its Major Tributaries of Eastern Himalayan Region of Nepal. Nepal Journal of Science and Technology, $10,219-223$.

[18] Mutenyo, I., Nejadhashemi, a P., Woznicki, S. a, \& Giri, S. (2013). Evaluation of SWAT Performance on a Mountainous Watershed in Tropical Africa. Hydrology Current Research, 14, 1-7. doi:10.4172/2157-7587.S14-001

[19] Ndomba, P. ., Mtalo, F. ., \& Killingtveit, A. (2005). Customizing SWAT Model in Data Poor and Complex Catchments. A Case of Pangani River, Tanzania (pp. 1-14).

[20] Green, C. H., Tomer, M. D., di Luzio, M., \& Arnold, J. G. (2006). Hydrologic evaluation of the soil and water assessment tool for a large tile-drained watershed in Iowa. Transactions of the ASABE, 49(2), 413-422. 
[21] Gassman, P. W., Reyes, M. R., Green, C. H., \& Arnold, J. G. (2007). The soil and water assessment tool: Historical development, applications, and future research directions. American Society of Agricultural and Bilogical Engineers, 50(4), 1211-1250. doi:10.1.1.88.6554

[22] Neupane, R. P., White, J. D., \& Alexander, S. E. (2015). Projected hydrologic changes in monsoon-dominated Himalaya Mountain basins with changing climate and deforestation. Journal of Hydrology, 525(APRIL), 216-230. doi:10.1016/j.jhydrol.2015.03.048

[23] Shukla, M. K. (2011). Soil Hydrology, Land use and Agriculture: Measurement and Modelling.

[24] Miller, J. D., Immerzeel, W. W., \& Rees, G. (2012). Climate Change Impacts on Glacier Hydrology and River Discharge in the Hindu Kush- Himalayas. Mountain Research and Development, 32(4), 461-467. 